\title{
Feds to scrutinize health disparities
}

$\mathrm{T}$ wo federal initiatives are in the pipeline that will provide, for the first time, a comprehensive statistical portrait of the state of health inequalities in Canada. Delegates to the Canadian Public Health Association annual meeting in Toronto got a first look at the upcoming pan-Canadian resources on May 28.

The first of these resources, a baseline reporting initiative led by the Public Health Agency of Canada (PHAC), will provide a "mile wide, inch deep" snapshot of disparities across 56 health indicators, broken down by various factors including sex, race, socioeconomic status and place of residence.

The other, an ongoing monitoring initiative led by the Canadian Institute for Health Information (CIHI), will track long-term trends and factors that influence health inequalities across a handful of priority indicators.

It's a first attempt to extensively catalogue how health inequalities affect Canadians, beyond just the poorest of the poor, in a bid to fulfill Canada's reporting obligations under the 2011 Rio Political Declaration on Social Determinants of Health.

"None of us live in a vacuum and we're all affected by many of these factors," Kim Elmslie, director general of PHAC's Centre for Chronic Disease Prevention and Control, told delegates. "There's a lot of good data out there, and now it's a matter of harnessing that data in the right way so that we can tell a compelling story about these disparities to policy-makers."

PHAC will incrementally expand its consideration of health equity across all "science functions, surveillance work and funding programs," Elmslie added. "We're now purposely requiring these programs to incorporate health inequality measurement and analysis into their

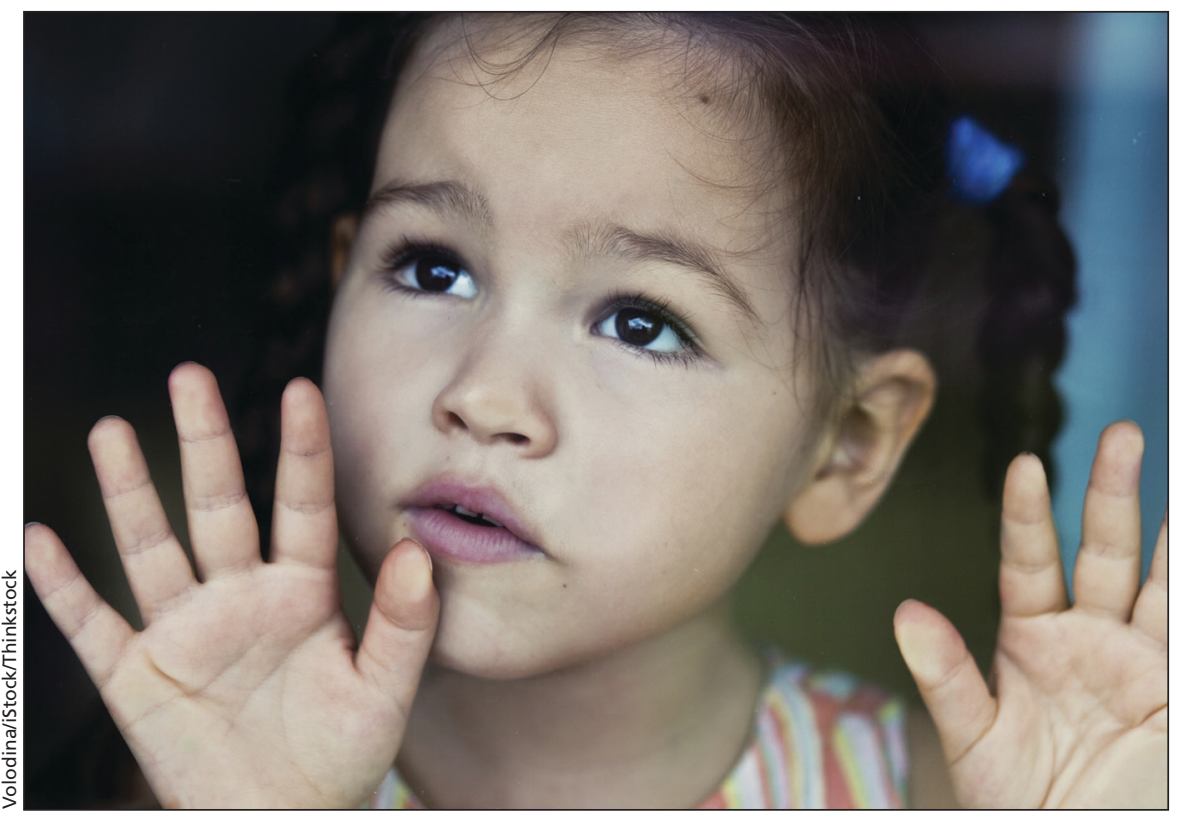

Two federal initiatives are a first attempt to extensively catalogue how health inequalities affect Canadians, beyond just the poorest of the poor.

work, not as an afterthought as has often been the case, but upfront in the planning and evaluation of activities."

The new initiatives will also compile information on promising policy options and interventions to address health disparities, but will stop short of providing specific recommendations for change.

Currently, "there are limitations with what you can present along with the data, and how far you can push the analysis if you're a federal government agency," said Dr. Cory Neudorf, Saskatoon Health Region chief medical officer of health, who moderated the presentation.

The studies' findings will also likely represent a "significant underestimation of inequality," because of limitations in the data available to researchers, he said.

According to Geoff Hynes, manager of CIHI's Canadian Population Health Initiative, trend data for Aboriginal populations, for example, "were unfortunately too difficult for us to find."

Hynes also provided a first glimpse at findings from CIHI's study. Among other trends, there's been relatively little progress on disparities linked to income since 2000 , he noted. "That's particularly interesting because there's been a tremendous amount of policy developed over that period, but for the most part these inequalities have persisted."

Meanwhile, the level of inequality Canadians experienced differed greatly depending on where they lived. For example, disparities in rates of hospital admissions for motor vehicle crashes were "much higher in Saskatchewan and Manitoba, versus Ontario and Quebec."

PHAC and CIHI will release full reports later this year. - Lauren Vogel, CMAJ

CMAJ 2014. DOI:10.1503/cmaj.109-4822 